\title{
Anti-proliferation, pro-apoptosis and anti-migration effects of ginkgolic acid C13:0 isolated from ginkgo biloba exocarp in MCF-7 and 4T-1 breast cancer cells
}

\author{
Da-Yu Zhou 1, Chun-Ying Jiang 2, Cheng-Hao Fu ' , Ping Chang ${ }^{2}$, Jia-Di Wu ${ }^{1}$, Ke-Xin Zheng \\ 1, Xiao-Hui Zhao ${ }^{3}$ and Shi-Liang Ma ${ }^{1,2, *}$ \\ 1 College of Food Science and Technology, Shenyang Agricultural University, Shenyang 110866, \\ China; zhoudayu09@aliyun.com (D.Y.Z.); happyflyfish@163.com (J.D.W.); zkx1988@hotmail.com \\ (K.X.Z.) \\ 2 College of Bioscience and Biotechnology, Shenyang Agricultural University, Shenyang 110866, \\ China; jcy_sn@sina.com (C.Y.J.); fuchenghaolab@Outlook.com (C.H.F.); chap93@126.com (P.C.) \\ 3 Department of Oncology, The First Affiliated Hospital of Jinzhou Medical University, Jinzhou \\ 121001, China; zhaoxiaohui9901@163.com (X.H.Z.) \\ * Correspondence: msl@syau.edu.cn (S.L.M.); Tel.:+86-024-88487163; Fax:+86-024-88492799
}

\begin{abstract}
Ginkgolic acids (GA) have been reported to exhibit anticancer properties, however, the mechanisms remain unclear. This study aims to investigate the mechanisms of GA C13:0 that was isolated from Ginkgo biloba exocarp (GBE) for anti-proliferation, pro-apoptosis and anti-migration effects in human MCF-7 and mouse 4T-1 breast cancer cells. The cytotoxic effect, apoptosis induction and migration inhibition were measured using MTT, TUNEL and Wound healing assays. The expression of mRNA and protein were determined using qPCR and Western blot. Our results showed that no cytotoxicity was found at concentrations of C13:0 below $100 \mu \mathrm{M}$. The effects of GA C13:0 was further demonstrated by up-regulation of the Bax/Bcl-2 apoptosis pathway and the expression of Apaf-1 protein in the mitochondria. In addition, GA C13:0 also suppressed cell migration and epithelial to mesenchymal transition (EMT) with the increase of E-cadherin expression accompanied by the decrease of Snail, MMP-2, MMP-9 and Vimentin expression. Moreover, GA C13:0 induced cytochrome P450 (CYP) $1 \mathrm{~B} 1$ expression in aryl hydrocarbon receptor (AhR) pathway. Notably, the up-regulation of CYP1B1 also might play a pivotal regulatory role in mitochondrial and EMT pathways in MCF-7 and 4T-1 cells. Our results may have implications for the development of anticancer agents containing GA as functional additives.
\end{abstract}

Keywords: Breast cancer; ginkgolic acid C13:0; mechanism; CYP1B1

\section{Introduction}

Breast cancer is the leading common neoplasm in women and cause significant rate of morbidity and mortality around the world [1]. The initiation and progression of breast cancer are ascribed to approximately $80 \%$ of external environmental factors, involving radiation, carcinogens, diet and so on. However, changes in dietary consumption appear to exert a great effect [2]. Some studies have shown that women consuming a high-fat diet are prone to enhance the risk of breast cancer compared with that in a low-fat diet in the Asian countries [3]. Epidemiological studies indicate that more intakes of plant food reduce the risk of breast cancer $[4,5]$. More and more studies also suggest that the prevention of cancer are strongly associated with the ingestion of natural bioactive compounds that exist principally in the organism of edible plants such as fruits, seeds and leaves $[6,7]$. Therefore, it is a prior 
necessity seeking the natural agents from edible plant for anticancer strategies [8].

Ginkgo biloba (GB) is an ancient edible and medicinal plant and has been cultivated extensively in the Asian countries [9]. The valuable organism of GB mainly includes leaves and fruits. EGB761 derived from Ginkgo leaves have reported to have efficient anticancer activity in the global drug development [10]. The fruits of GB are known as ginkgo nuts for functional foods, which have been used for the treatment of malignant neoplasm in the traditional Chinese medicine [11]. About 75\% of the total fruit weight of the GBE, which are often treated as discarded waste have been reported to provide significant anticancer effects in vitro [12]. In order to develop the resources of Ginkgo biloba more fully, GBE pharmacological effects have been exploited and attributed to the composition of flavonoids (kaempferol, quercetin and isorhamnetin) and terpene trilactones (bilobalide and ginkgolide) as well as phenolic acids (mainly GA). GA are mixtures of GA homologues (C13:0,C15:1,C17:2,C15:0,C17:1), which are abundant in GBE exhibit a wide range of interesting pharmacological effects, involving antioxidant [13], anti-inflammatory [14], anti-HIV [15] , anti-bacterium [16] and anticancer activities [17, 18]. Unfortunately, GA have been reported to contain toxic and allergenic potential [19].Thus, the maximal concentration of GA monomer compound has been restricted to 5ppm for application in the National Pharmacopoeia monographs. However, studies have shown that GA C13:0 at the concentrations of $25 \mu \mathrm{M}(8 \mathrm{ppm})$ and $100 \mu \mathrm{M}(32 \mathrm{ppm})$ are used for inhibiting invasion and migration in MCF-7 and MDA-MB-231 (human breast cancer cells) [20]. GA C15:1 and C17:1 at $100 \mu \mathrm{M}(25 \mathrm{ppm})$ and $40 \mu \mathrm{M}(11 \mathrm{ppm})$ are used for pro-apoptosis and anti-migration in A549 and H1299 (human lung cancer cells) [17], and Tac8113 (human tongue squamous carcinoma cells) [21], suggesting that the maximal concentration of GA may be reassessed for pharmacological effects on anticancer activity.

GA C13:0 belongs to the alkyl phenols and offers a higher suppressed migratory behavior compared with the other GA homologues in MCF-7 breast cancer cells [20]. Moreover, GA C13:0 also inhibits migration through suppression of NEMO sumoylation and NF- $\kappa$ B activity in MDA-MB-231 breast cancer cells [20]. However, no studies have provided conclusive mechanisms of action regarding the effects of GA C13:0 in human MCF-7 and mouse 4T-1 breast cancer cells. In our previous study, the fruit of GB extract showed inhibited proliferation in MCF-7 and MDA-MB-231 breast cancer cells and that accompanied by the enhancement of CYP1B1 mRNA expression [22]. In this study, we isolated GA C13:0 from the GBE and investigated the anti-proliferation, pro-apoptosis and anti-migration effects as well as the possible pivotal regulatory role of CYP1B1 in breast cancer cells.

\section{Results and discussion}

\subsection{Isolation and comparison of GA C13:0 in MCF-7 and 4T-1 cells}

In this study, the MTT assay guided isolation of GA C13:0 from GBE in MCF-7 and 4T-1 cells was evaluated for the anticancer effects. As shown in Figure.1A, the ethanol extract of GBE showed the stronger anti-breast cancer activity with the IC50 value of 283.05 and $179.31 \mu \mathrm{g} / \mathrm{mL}$ compared with the water extract with the IC50 value of 691.86 and $440.32 \mu \mathrm{g} / \mathrm{mL}$ in MCF-7 and $4 \mathrm{~T}-1$ cells, respectively. Thus, ethanol was chosen as the optimal solvent for further extraction. Among the four fractions of the ethanol extract, 
Fr.1, the fraction of petroleum ether, exhibited the higher cytotoxicity with the IC50 values of 140.21 and $117.23 \mu \mathrm{g} / \mathrm{mL}$ (Figure.1B), compared with the other fractions and selected for purification. Isolation of Fr.1 afforded nine subfactions. Subfr.4 exhibited the higher cytotoxicity with the IC50 values of $108.62 \mu \mathrm{g} / \mathrm{mL}$ and $95.77 \mu \mathrm{g} / \mathrm{mL}$ and selected for further purification (Figure.1C). Subfr.4 divided into five fractions. Subfr.4-2, the ingredient was GA C13:0 (Figure.1F, S1 and S2), which was identified using HPLC-MS presented the highest cytotoxicity with the IC50 values of $53.82 \mu \mathrm{g} / \mathrm{mL}$ and $42.51 \mu \mathrm{g} / \mathrm{mL}$ in MCF-7 and 4T-1 cells, respectively (Figure.1D).These results suggested that the GA C13:0 might be responsible for the cytotoxic effect of the GBE extract and the other fractions and subfractions with lower cytotoxicity were not further isolated. Some studies demonstrate that other phenolic acids with different side chain structures, such as gallic acid, chlorogenic acid, caffeic acid and salicylic acid have significantly cytotoxic effects in MCF-7 and MDA-MB-231 cells, but through different mechanisms of inhibition [23, 24].
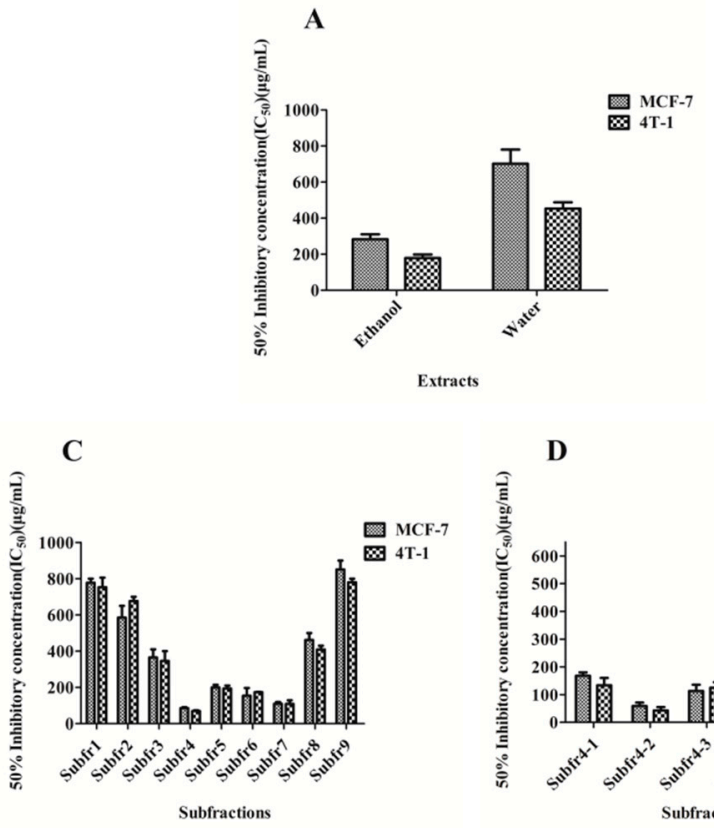

D

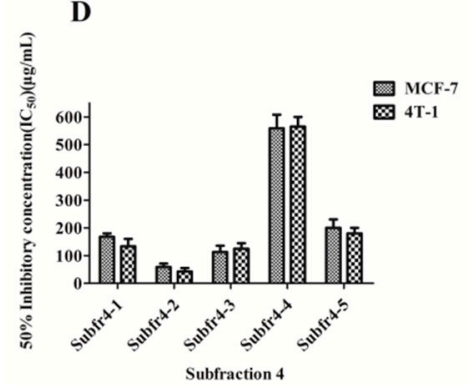

$\mathbf{F}$

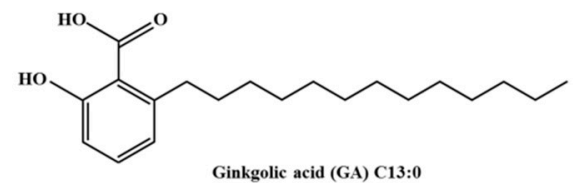

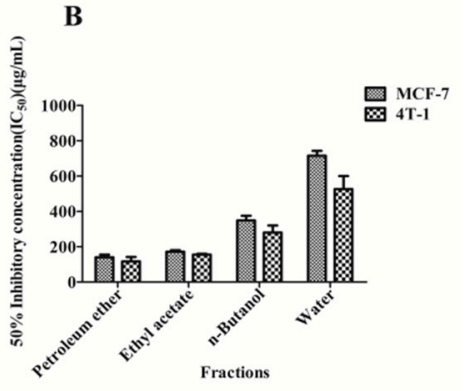

E

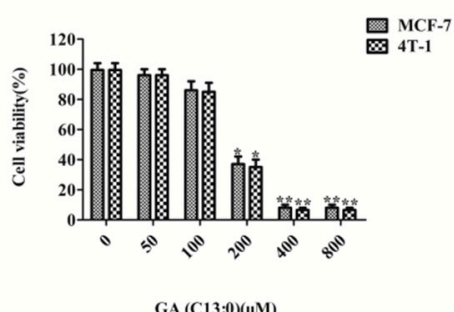

GA (C13:0)( $(\mu \mathrm{M})$

\begin{abstract}
Figure 1. The cytotoxic effects of Extracts, Fractions, Subfractions, Subfraction 4 and ginkgolic acid (GA) C13:0 in MCF-7 and 4T-1 cells. The IC50 was detected by MTT assay. Both cells were incubated with different concentrations of Extract (A), Fractions (B), Subfractions (C), Subfraction-4 (D), $(0-800 \mu \mathrm{g} / \mathrm{mL})$ and GA C13:0 (E), $(0-800 \mu \mathrm{M})$ for 24h. The chemical structure of GA C15:1 (F). The data were means $\pm \mathrm{SD}$ for three replicates per treatment. $\left({ }^{*} \mathrm{P}<0.05\right.$ and ${ }^{* *} \mathrm{P}<0.01$ compared with 0.05\%DMSO-treated control cells).
\end{abstract}

Besides GA C13:0, there are many special active compounds of flavonoids and terpenoids in GBE. To further determine the predominant effect of GA C13:0, the comparison of GA C13:0 and the special standard compounds, involving ginkgolic acids 
(GAs), quercetin, kaempferol, isorhamnetin, bilobalide and ginkgolide B were examined in MCF-7 and 4T-1 cells. The lethal effect of these compounds at the concentration of $400 \mu \mathrm{M}$ was evaluated using trypan blue dye exclusion assay. As shown in Figure. 2A and 2B, the lethal effect of GA C13:0 was higher than GAs group insignificantly, with cell death rate of $90.71 \%, 87.34 \%$ and $95.57 \%, 91.22 \%$ in MCF-7 and $4 \mathrm{~T}-1$ cells, respectively, and had more significant difference compared with the control and other active groups. Therefore, our results demonstrated that the GA C13:0 had a powerful cytotoxic effect in MCF-7 and 4T-1 cells and represented a source of excellent natural anti-breast cancer compound in GBE.
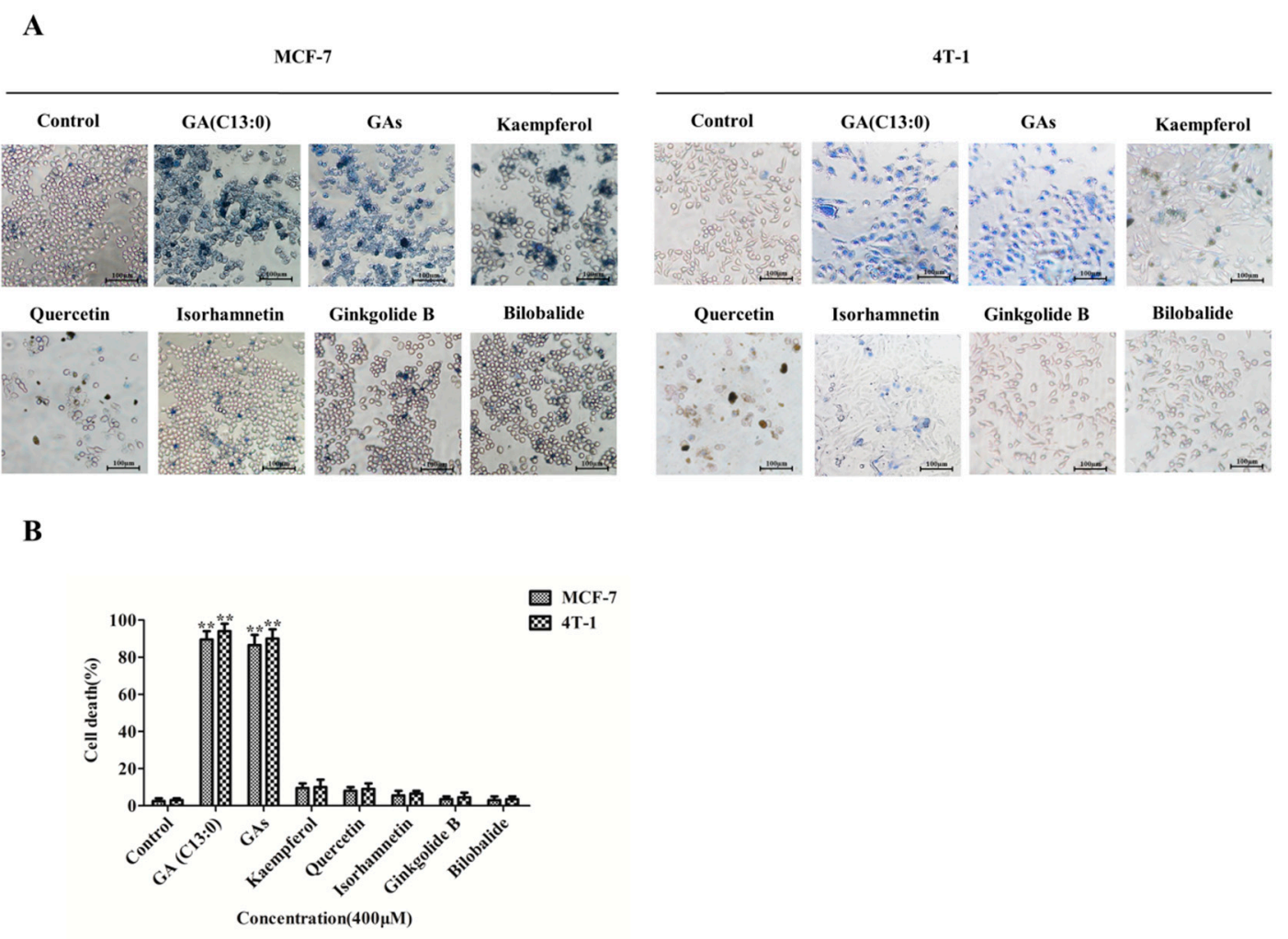

Figure 2. The comparison of ginkgolic acid (GA) C13:0 and the active compounds in MCF-7 and 4T-1 cells. The effect of GA C13:0 and the standards of Ginkgolic acids (GAs), Kaempferol, Quercetin, Isorhamnetin, Ginkgolide B and Bilobalide were examined in MCF-7 and 4T-1 cells at concentration of $400 \mu \mathrm{M}$ for $24 \mathrm{~h}$. Cell death (blue) was observed by trypan blue dye exclusion assay (A). The cell death rate was determined from the ratio of the number of nonviable (stained) cells to the total number of cells (B).The data were represented as the mean \pm SD from three independent experiments. $\left({ }^{*} \mathrm{P}<0.05\right.$ and ${ }^{* *} \mathrm{P}<0.01$ compared with $0.05 \% \mathrm{DMSO}-$ treated control cells).

\subsection{Assessment of cytotoxicity and anti-proliferation of GA C13:0 in MCF-7 and 4T-1 cells}

To analyze the cytotoxic and anti-proliferative effects in the MCF-7 and 4T-1 cells, the cells were treated with GA C13:0 at various concentrations for $24 \mathrm{~h}$ and the cell viability was determined using MTT assay, trypan blue dye exclusion assay and anti-proliferative assay. As shown in Figure.1E, the cytotoxic effect of GA C13:0 was more significant at concentrations over $200 \mu \mathrm{M}$ and the cell viability rate were less than $40 \%$ 
132

133

134

135

136

137

138

139

140

141

compared with the control group in MCF-7 and 4T-1 cells. However, no significant cytotoxicity was noted at concentrations of GA C13:0 below 100 $\mu \mathrm{M}$ and the cell viability rate were more than $85 \%$ compared with the control group. Additionally, we also observed that the death rates were $91.45 \%$ and $95.02 \%$ at concentration of $400 \mu \mathrm{M}, 59.75 \%$ and $62.02 \%$ at $200 \mu \mathrm{M}, 19.27 \%$ and $21.14 \%$ at $100 \mu \mathrm{M}$, and $5.02 \%$ and $4.88 \%$ at $50 \mu \mathrm{M}$ compared with the control group in MCF-7 and 4T-1 cells, respectively (Figure.3A,3B).The anti-proliferation of GA C13:0 was shown in Figure.3C,3D, the percent survival of cells were less than $5 \%$ at concentration of $400 \mu \mathrm{M}$, less than $40 \%$ at $200 \mu \mathrm{M}$, less than $80 \%$ at $100 \mu \mathrm{M}$ and nearly $90 \%$ at $50 \mu \mathrm{M}$ compared with the control group in MCF-7 and 4T-1 cells, respectively.

$\mathbf{A}$

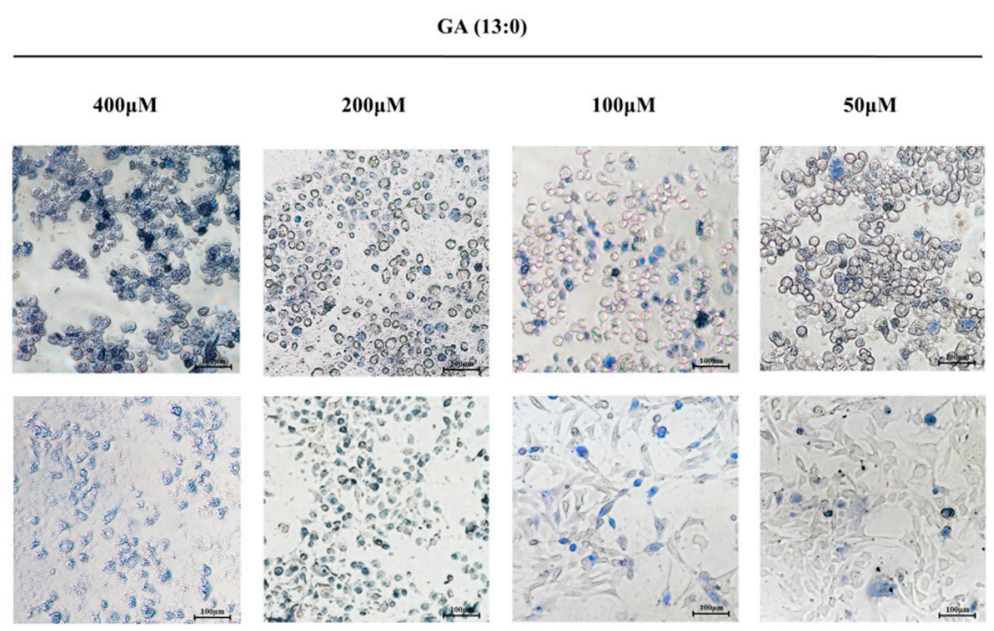

B

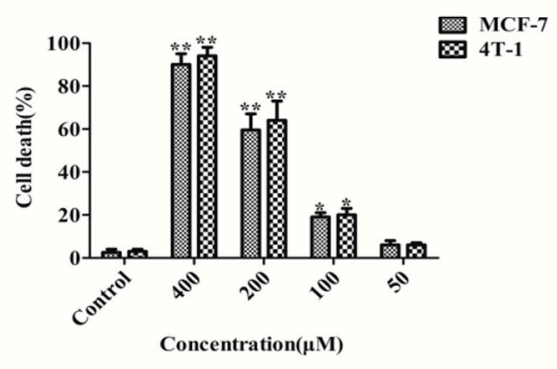


$\mathbf{C}$

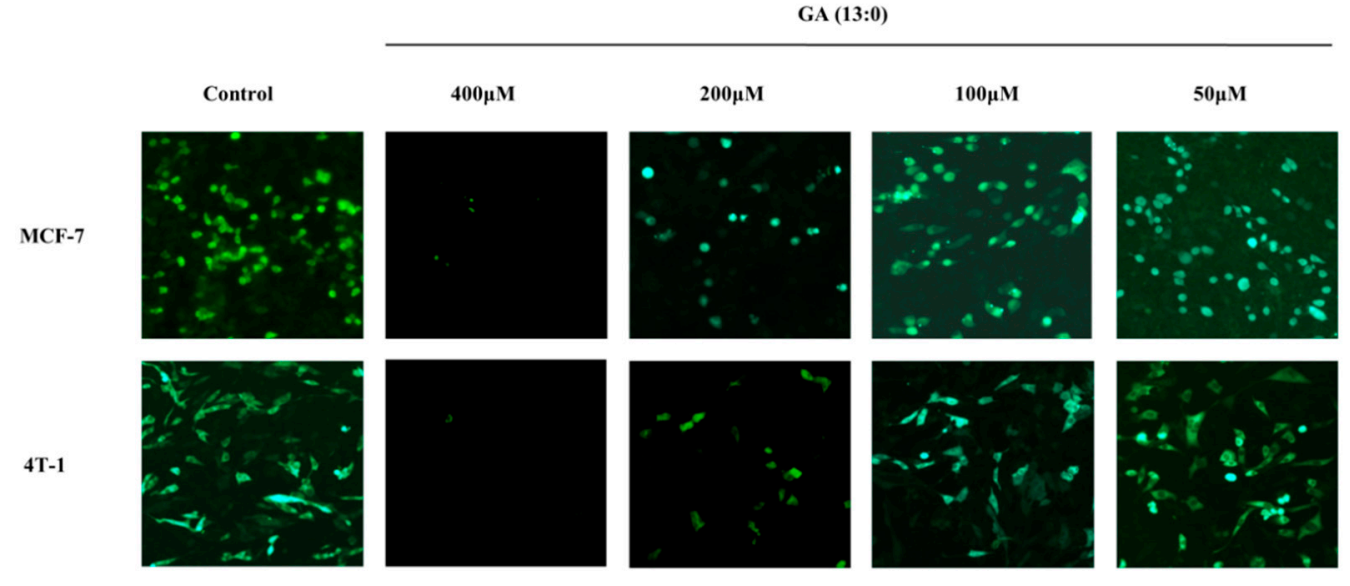

D

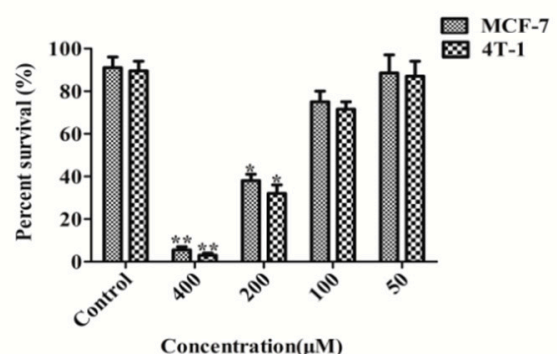

Figure 3. Assessment of cytotoxicity and anti-proliferation of GA C13:0 in MCF-7 and 4T-1 cells.

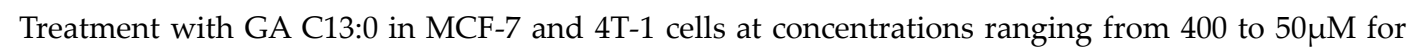
24h. Cell death (blue) was observed by trypan blue dye exclusion assay (A). Cell death rate was determined from the ratio of the number of nonviable (stained) cells to the total number of cells (B). The surviving cells with green fluorescent protein (GFP) were observed by inverted fluorescence microscope (C).The percent survival of cells were performed from the ratio of the number of GFP cells to the total number of cells (D). The data were represented as the mean $\pm \mathrm{SD}$ of three independent experiments. $\left({ }^{*} \mathrm{P}<0.05\right.$ and ${ }^{* *} \mathrm{P}<0.01$ compared with $0.05 \%$ DMSO-treated control cells).

Virtually, in the National Pharmacopoeia monographs, the concentration of GA C13:0 has been restricted to $5 \mathrm{ppm}(16 \mu \mathrm{M})$ for pharmaceutical agents. Studies have reported that the concentrations of GA C13:0 over $25 \mu \mathrm{M}$ with no cytotoxicity are used for MCF-7 and MDA-MB-231(human breast cancer cells) [20], A549 (human lung cancer cells) and SMMC7721 (human liver cancer cells) [25]. However, our results suggested that no cytotoxic effect of GA C13:0 was observed at concentrations below 100 $\mu \mathrm{M}$ and the anti-proliferation of GA C13:0 appeared increase in a dose dependent manner compared with the control group in MCF-7 and 4T-1 cells.

\subsection{Apoptosis induction of GA C13:0 in MCF-7 and 4T-1 cells}

After incubation with GA C13:0 at concentrations ranging from $200 \mu \mathrm{M}$ to $25 \mu \mathrm{M}$ for $24 \mathrm{~h}$, TUNEL and DAPI staining assay was performed to determine whether GA C13:0 could induce apoptosis in MCF-7 and 4T-1 cells. The expression of related proteins in 

apoptosis including B-cell lymphoma 2 (Bcl-2), Bcl-2-associated X (Bax) and Apoptotic protease-activating factor-1 (Apaf-1) were examined by Western blot assay. Figure.4A showed that treatment with GA C13:0 at the different concentrations, the morphological changes of cells in the different stages of apoptosis, such as chromatin condensation and marginalization, nuclear fragmentation and the production of apoptotic bodies were clearly observed (red arrows) by inverted fluorescent microscopy. The other morphological changes were not proposed as apoptotic cells. However, the inability of

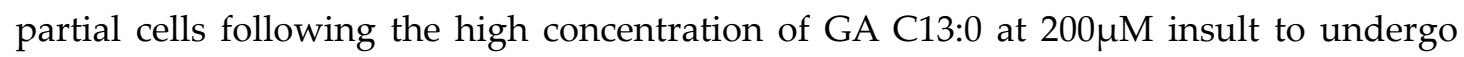
chromatin condensation and nuclear fragmentation (white arrows). A similar change was previously reported for DAPI staining [26].Therefore, the apoptotic cells appeared 20.33\% and $20.41 \%$ at concentration of $200 \mu \mathrm{M}, 26.33 \%$ and $29.41 \%$ at $100 \mu \mathrm{M}$ in MCF-7 and $4 \mathrm{~T}-1$ cells, respectively, and no significant differences were observed in apoptosis at concentrations below $50 \mu \mathrm{M}$ compared with the control group (Figure.4B)

A GA (C13:0)

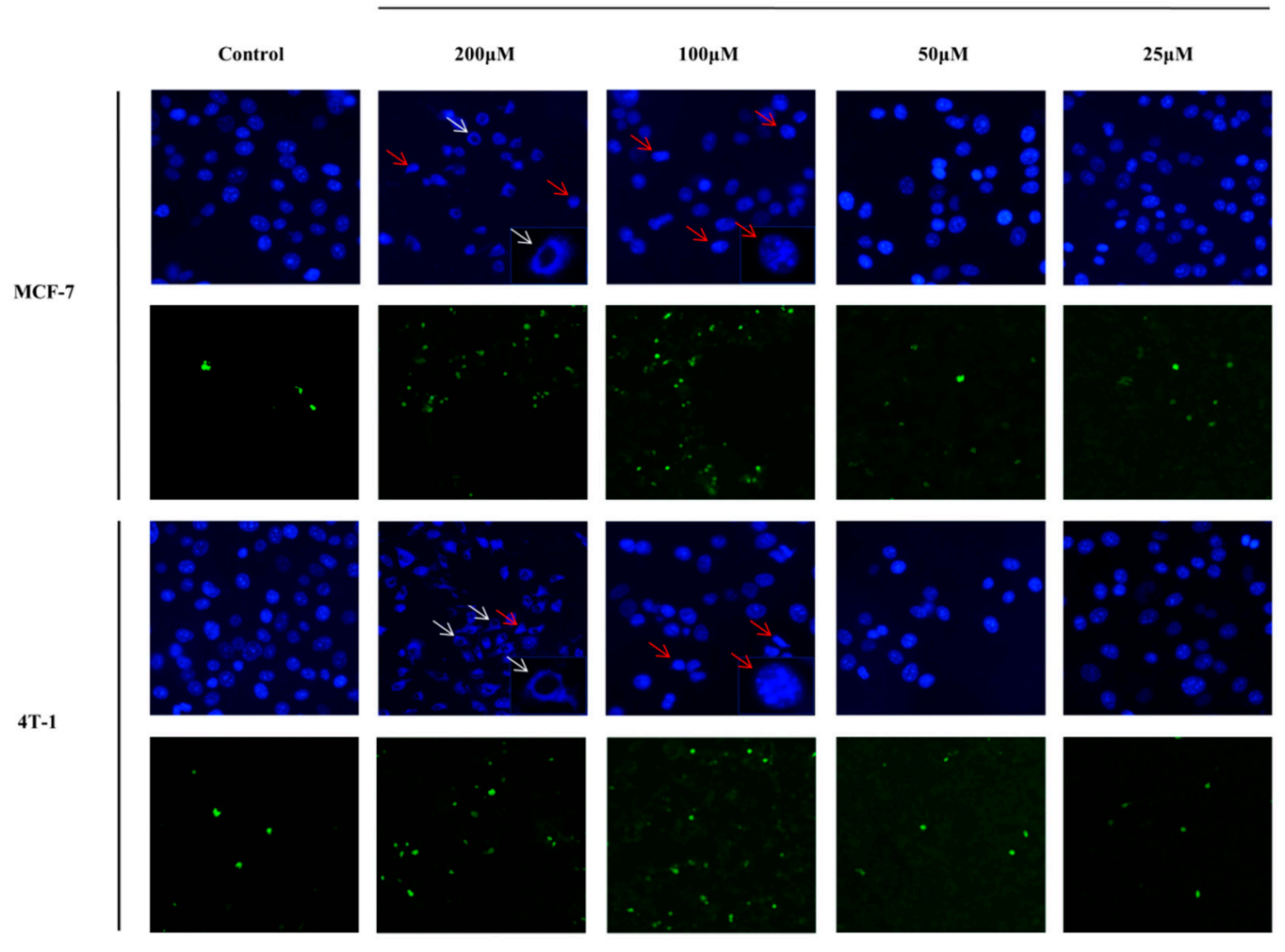

B

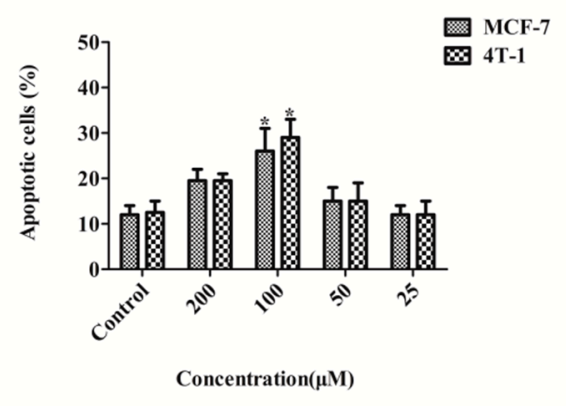




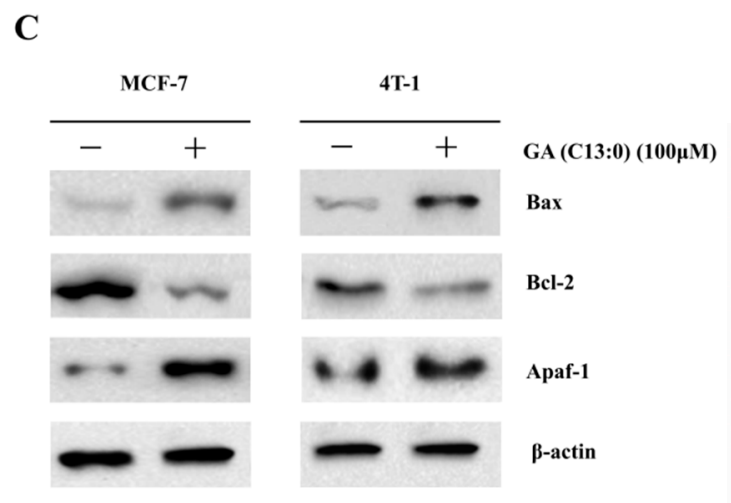

180

181

182

183

184

185

186

187

188

189

190

191

192

193

194

195

196

197

198

199

200

201

202

203

204

205

206

207

208

209

210

211

212

Figure 4. Apoptosis induction of GA C13:0 in MCF-7 and 4T-1 cells. Effect of GA C13:0 on apoptosis in MCF-7 and 4T-1 cells by DAPI, TUNEL and Western blot analysis. Treatment with GA C13:0 at concentrations ranging from 200 to $25 \mu \mathrm{M}$ for $24 \mathrm{~h}$, apoptotic cells were observed by DAPI and TUNEL assay using inverted fluorescence microscope. Red arrows showed the apoptotic cells and white arrows showed the unstained nuclear of cells following toxic insult of the high concentration of GA C13:0 at 200 $\mu \mathrm{M}$ (A).The apoptotic cells were determined from the ratio of the number of apoptotic cells to the total number of cells. (B). Western blot analysis was detected for the expression

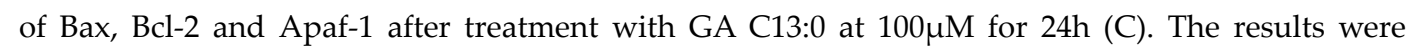
represented as the mean $\pm \mathrm{SD}$ from three independent experiments. $\left({ }^{*} \mathrm{P}<0.05\right.$ and ${ }^{* *} \mathrm{P}<0.01$ compared with $0.05 \%$ DMSO-treated control cells).

Western blot analysis showed that the concentration of GA C13:0 at 100 $\mu \mathrm{M}$ significantly induced Bcl-2 protein expression level decrease, the Bax and Apaf-1 protein expression levels increase in MCF-7 and 4T-1 cells (Figure.4C). Apoptosis, a mode of programmed cell death, has a strict and complex signal transduction pathway and is induced through the activation of either extrinsic receptor mediated apoptosis pathways or intrinsic mitochondria-dependent pathways [27, 28]. Bax, a pro-apoptotic protein, has been regulated by an anti-apoptotic protein of Bcl-2, which is located in the outer mitochondrial membrane. Mitochondria-associated Bcl-2 suppresses Bax/Bak oligomerization and the formation of pores through which cytochrome $C$ can be released into the cytosol, and initiate with Apaf- 1 formation of the apoptosome [29]. The Bax/Bcl-2 ratio and Apaf-1 expression increase have been considered as an indicator of apoptosis in the intrinsic mitochondria death pathways [30, 31]. Overall, our results illustrated that the concentration of GA C13:0 at 100 $\mu \mathrm{M}$ significantly induced apoptosis in MCF-7 and 4T-1 cells through increased the Bax/Bcl-2 ratio and Apaf-1 protein expression levels in mitochondrial death pathway.

\subsection{Anti-migration activity of GA C13:0 in MCF-7 and 4T-1 cells}

To assess the effect of GA C13:0 on the migration activity of MCF-7 and 4T-1 cells with no anti-proliferative effect, wound healing assay was performed and the expression of related proteins, involving Snail, MMP-2, MMP-9, Vimentin and E-cadherin were examined. As shown in Figure.5A and 5B, GA C13:0 inhibited migration significantly at concentrations ranging from 50 to $25 \mu \mathrm{M}$ for $48 \mathrm{~h}$ compared with the control group. Western blot analysis showed that GA C13:0 $(50 \mu \mathrm{M})$ decreased the expression of Snail, MMP-2, MMP-9, Vimentin, and increased E-cadherin expression significantly in MCF-7 

and 4T-1 cells (Figure.5C).

A

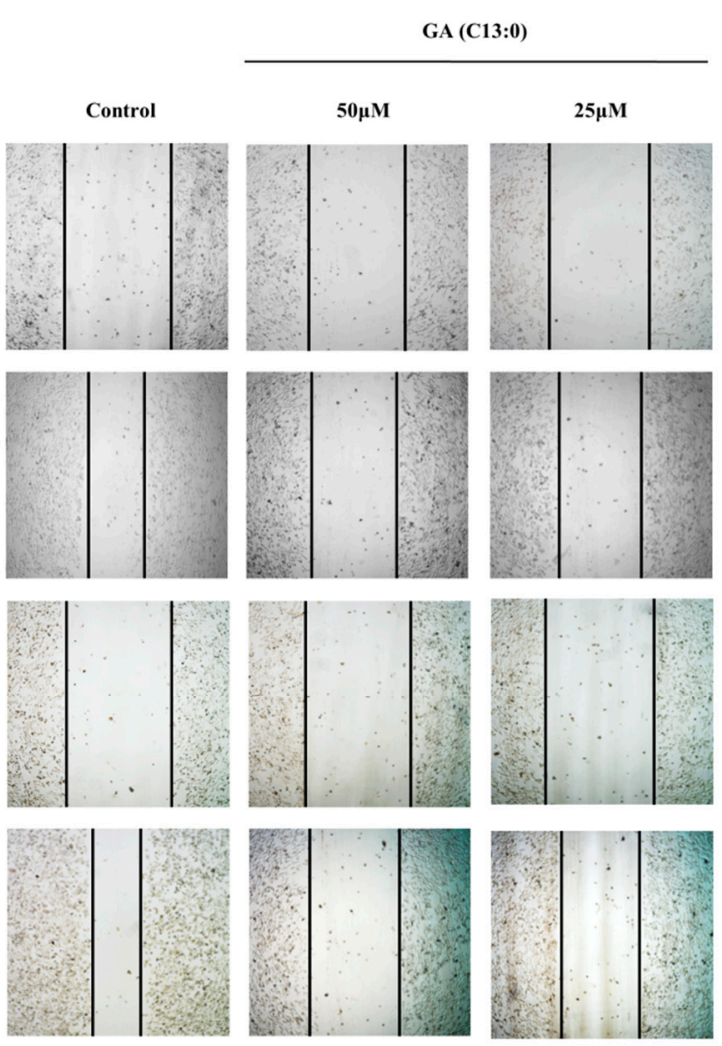

214

B

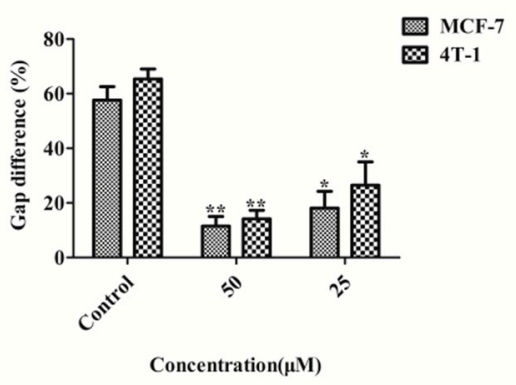

215

C
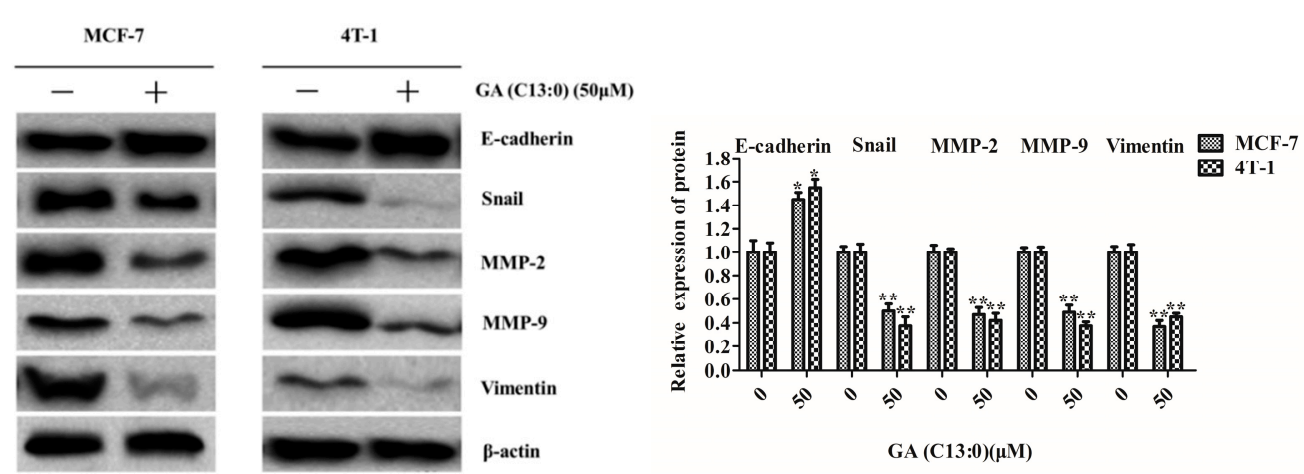

217 Figure 5. Anti-migration activity of GA C13:0 in MCF-7 and 4T1 cells. Wound healing assay was
218 performed for evaluating the anti-migration effect of GA C13:0. The confluent monolayers of MCF-7 
and 4T-1 cells were scarred and treated with serum-free medium plus the concentrations of GA $\mathrm{C} 13: 0$ at $50 \mu \mathrm{M}$ and $25 \mu \mathrm{M}$ for $48 \mathrm{~h}$. The wound was observed using a light microscopy and images were taken at area of the wound at time 0 and $48 \mathrm{~h}$ of incubation. Black lines indicate the wound edge (A). Gap difference of the wound was measured. The data were normalized to the average of the control and images were plotted against the percentage of migration distance the cells moved before and after treatment (B). MCF-7 and 4T-1 cells were incubated with 50 $\mu$ M of GA C13:0 for $48 \mathrm{~h}$, then Western blot analysis was detected for the expression of Snail, MMP-2, MMP-9, Vimentin and E-cadherin $(\mathrm{C})$. The results represented mean $\pm \mathrm{SD}$ values of three measurements. $\left({ }^{*} \mathrm{P}<0.05\right.$ and ${ }^{* *} \mathrm{P}$ $<0.01$ compared with $0.05 \%$ DMSO-treated control cells).

In the process of cancer metastasis, EMT is the initial process in cancer progression and is triggered by the expression changes of genes of epithelial and mesenchymal specific in cancer cells. The occurrence of EMT allows epithelial cells lose their adhesion and acquire the capacity of invasion and migration [32]. More evidence for the EMT is regulated mainly by several epithelial proteins (E-cadherin and keratins) and mesenchymal proteins (vimentin and MMPs). MMP-2 and MMP-9 are closely associated with the processes of invasion and migration in various cancer cells [33]. Thus, the decrease of E-cadherin expression and the increase of Vimentin, MMP-2 and MMP-9 expression are representative characteristic of EMT [34]. Studies also have reported that GA C13:0 exerts anti-EMT effects by inhibited the NF- $\kappa B$ activity and down-regulation of uPA, PAI-1 and MMP-9 expression on MDA-MB-231 cells [20]. GA C15:1 also suppress migration and EMT transition by decreased protein expression of Snail, Vimentin, MMP-2 and MMP-9 on A549 and H1299 cells [17]. Therefore, our data suggested that the concentration of GA C13:0 at 50 $\mathrm{M}$ suppressed migration and EMT effects through up-regulated E-cadherin and down-regulated Snail, MMP-2, MMP-9 and Vimentin protein expression in MCF-7 and 4T-1 cells.

\subsection{Effects of CYP1A1, CYP1B1 and AhR expression of GA C13:0 in MCF-7 and 4T-1 cells}

To further ascertain the mechanism of inhibition effect of GA C13:0 in MCF-7 and 4T-1

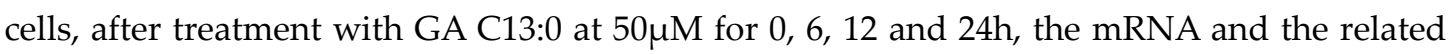
proteins of CYP1A1, CYP1B1 and AhR were assayed by RT-PCR and Western blot. As shown in Figure.6A, GA C13:0 induced the CYP1B1 and AhR mRNA levels increase significantly in time dependent manner compared with the control group. Treatment for 6, 12 and $24 \mathrm{~h}$ increased CYP1B1 mRNA levels by 1.3-fold and 1.9-fold, 1.5-fold and 3.0-fold, and 2.3-fold and 5.0-fold, respectively, in MCF-7 and 4T-1 cells. Similarly, that increased AhR mRNA levels by 1.4-fold and 1.6-fold, 2.1-fold and 3.0-fold, and 3.3-fold and 5.1-fold, respectively, in both cells. However, the CYP1A1 mRNA levels exhibited no significant changes compared with the control group. Western blot assay showed that treatment of GA C13:0 did not affect CYP1A1 protein expression, whereas that significantly increased CYP1B1 and AhR protein expression compared with the control group in MCF-7 and 4T-1 cells (Figure.6B). 
A
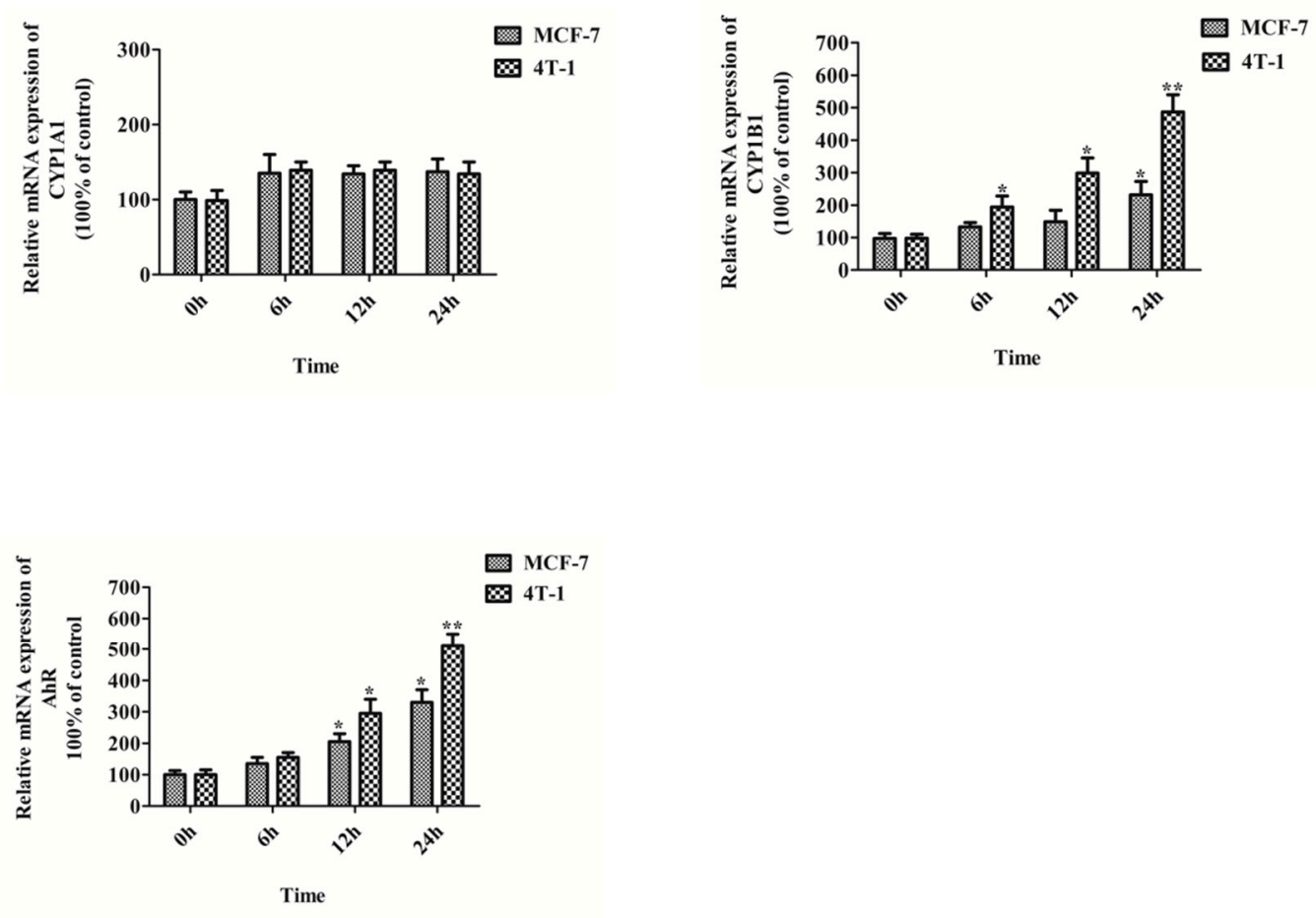

B
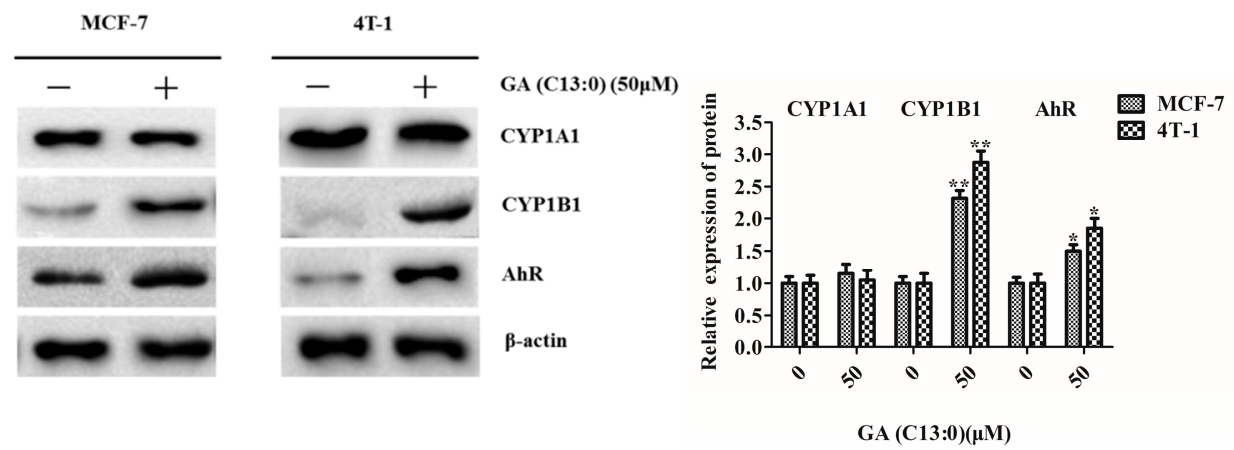

Figure 6. Effects of GA C13:0 on the modulation of CYP1A1, CYP1B1 and AhR expression in MCF-7

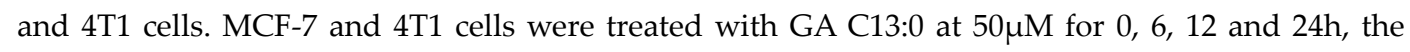
mRNA was extracted and the CYP1A1, CYP1B1 and AhR were examined by qPCR (A). Western blot analysis was detected for the expression of CYP1A1, CYP1B1 and AhR, after treatment with GA $\mathrm{C} 13: 0$ at $50 \mu \mathrm{M}$ for $24 \mathrm{~h}(\mathrm{~B})$. The results were represented as the mean $\pm \mathrm{SD}$ from three independent experiments. $\left({ }^{*} \mathrm{P}<0.05\right.$ and ${ }^{* *} \mathrm{P}<0.01$ compared with $0.05 \% \mathrm{DMSO}$-treated control cells).

$\mathrm{AhR}$ is a ligand-activated transcriptional factor, which binds to specific aromatic hydrocarbons regulates the expression of downstream genes including CYP1 family members: CYP1A1 and CYP1B1 [35]. Distinct from CYP1A1, which is detected in only a few tumors, CYP1B1 has been proposed as a potential target on the basis of investigation that this enzyme has catalyzed activation of various compounds to metabolites, which induce DNA damage have anticancer activity [21]. CYP1B1 has catalyzed 17b-estradiol to 
4-hydroxyestradiol metabolite, which induce cellular damage has been implicated in the initiation stages of mammary tumors [36]. CYP1B1 and CYP1A1 also are shown to metabolise eupatorin to the flavone cirsiliol and catalyze conversion of diosmetin to flavone luteolin, which exhibits inhibitory action in MDA-MB-468 breast cancer cells [37, 38]. In our study, the results indicated that GA C13:0, which belongs to the aromatic hydrocarbons could up-regulate the expression of AhR and induce CYP1B1 increase in AhR signaling pathway in MCF-7 and 4T-1 cells. However, in contrast to CYP1B1, the expression of CYP1A1 had no significant changes compared with the control group. The reason for these may be attributed to the alkyl phenolic structure of GA C13:0. Moreover, the anticancer activities of metabolites, which were generated from GA C13:0 due to CYP1B1 catalytic role are required further studies to be confirmed.

Additionally, CYP1B1 has supposed to play a key role by targeting multiple components of the cell apoptosis and metastatic pathways that are involved in many tumor cells, including prostate cancer [39], endometrial cancer [40] as well as breast cancer [41]. CYP1B1 plays a vital regulatory role to affect EMT and activate Wnt/ß-catenin signaling via regulation of Snail, Zeb2,Twist1, MMPs, E-cadherin and Vimentin in MCF-7 breast cancer cells [41]. CYP1B1 also has induced apoptosis through regulate the expression of caspase-1, tumor necrosis factor receptor superfamily, member 9 (Tnfrsf-9), CD27 molecule as well as Harakiri, which is Bcl-2 interacting protein on PC-3 prostate cancer cells [39]. In this study, our results indicated that the up-regulation of CYP1B1 was accompanied by the changes of related proteins expression, including Bcl-2, Bax, Apaf-1, Snail, MMP-2, MMP-9, Vimentin and E-cadherin (Figure.7). Therefore, the induction of CYP1B1 by GA C13:0 might play a pivotal role in mitochondrial apoptosis and EMT migration pathways in MCF-7 and 4T-1 cells. Further studies are needed to confirm these associations.
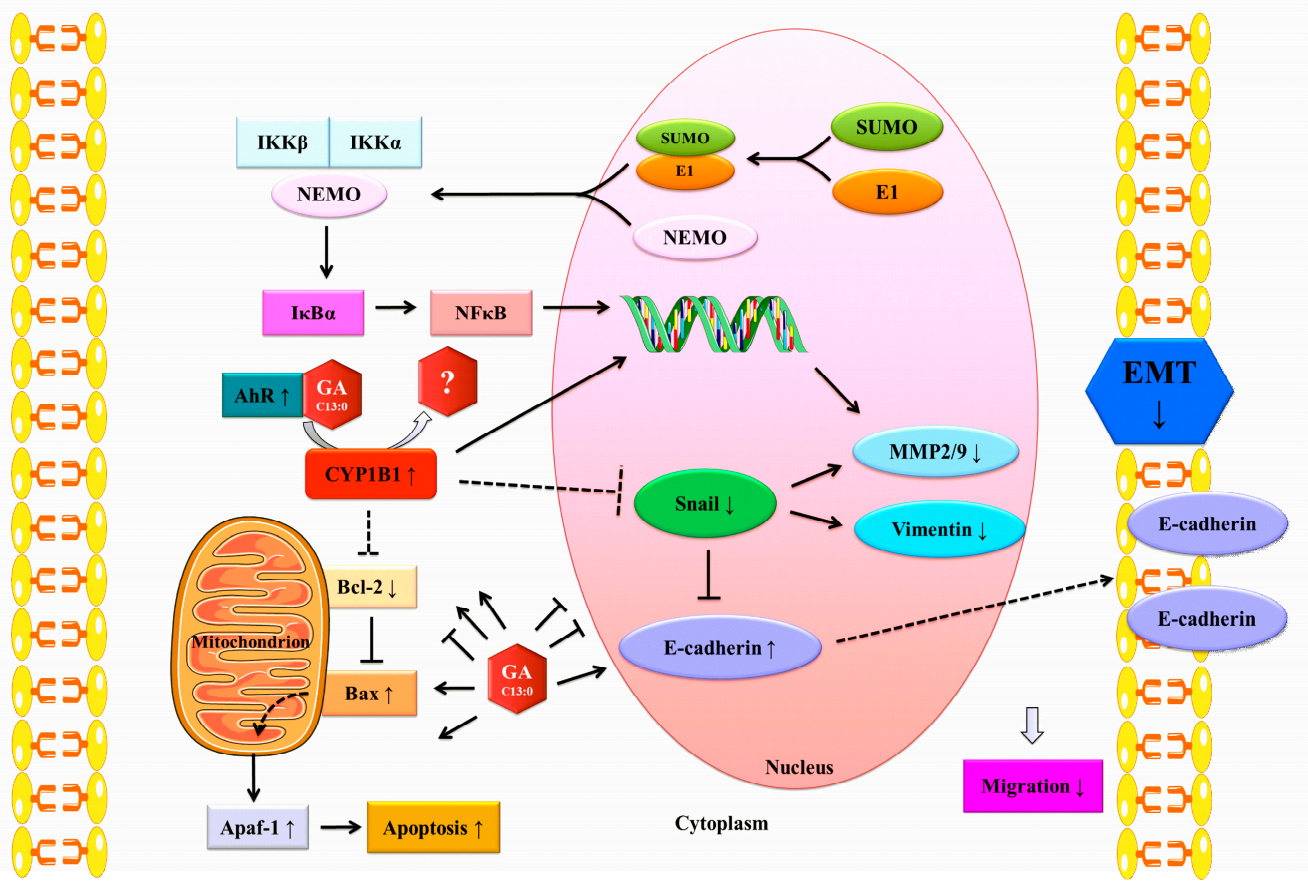

Figure 7. Scheme for the possible mechanisms of CYP1B1 action. Diagram showed the mechanism of GA C13:0 on the multiple pathways and the possibility of associations among the mitochondrial 
apoptosis, EMT as well as the vital regulatory role of CYP1B1 in MCF-7 and 4T-1 cells.

299

300

301

302

303

304

305

306

307

308

309

310

311

312

313

314

315

316

317

318

319

320

321

322

323

324

325

326

327

328

329

330

331

332

333

334

335

336

\section{Materials and methods}

\subsection{Chemicals, standards and reagents}

HPLC-grade methanol was purchased from TEDIA (Fairfield,OH, USA). All other solvents were of analytical grade. Column chromatography was performed over silica gel (200-300 mesh, Qingdao Haiyang Chemical Co., Ltd., Qingdao, China). Standards such as ginkgolic acids, quercetin, kaempferol, isorhamnetin, bilobalide and ginkgolide $\mathrm{B}$ were purchased from the National Institute for the Control of Pharmaceutical and Biological Products (Beijing, China). 3-(4,5-dimethylthiaxolone-2-yl)-2,5-diphenyltetrazoliumbromide (MTT), dimethyl sulfoxide (DMSO), RPMI1640 medium, fetal bovine serum, penicillin/streptomycin, sodium pyruvate, Trypsin-EDTA were purchased from Sigma-Aldrich (St. Louis, MO, USA).The primary antibodies for anti-MMP-2, anti-MMP-9, anti-Vimentin, anti-E-cadherin, anti-Snail, anti-Apaf-1, anti-Bax, anti-Bcl-2, anti-CYP1A1, anti-CYP1B1 and anti-AhR were purchased from Sigma-Aldrich (St. Louis, MO, USA). Anti- $\beta$-actin and other secondary antibodies were obtained from En Jing (Beijing, China).

\subsection{Cytotoxic assay guided isolation of GA C13:0}

The fresh GBE were collected from Shenyang Agricultural University campus in Liaoning province of China and identified according to the application standard of Pharmacopeia of China. The exocarp were cleaned, cut and minced carefully. The two fresh samples (each $1 \mathrm{~kg}$, water content $52.82 \%$ ) were macerated separately in $10 \mathrm{~L}$ ethanol and water at room temperature for $24 \mathrm{~h}$ and then treated with shaking for $4 \mathrm{~h}$. Solvent removal using a rotary evaporator under reduced pressure at $37^{\circ} \mathrm{C}$, and the extraction was achieved with the vacuum drying oven (Salvis,VC20, Switzerland) to give 12.48g and 11.66g of brown solids, respectively. Among these, the ethanol extract showed higher cytotoxic effect in MCF-7 and 4T-1 cells (Figure.1A). The ethanol extract was suspended in water $(100 \mathrm{~mL})$ and partitioned successively in increasing order of polarity by petroleum ether $(3 \times 100 \mathrm{~mL})$, ethyl acetate $(3 \times 100 \mathrm{~mL})$ and $\mathrm{n}$-butanol $(3 \times 100 \mathrm{~mL})$ consecutively, giving petroleum ether $(1.22 \mathrm{~g})$, ethyl acetate (1.63), n-butanol $(1.07 \mathrm{~g})$ and $\mathrm{H}_{2} \mathrm{O}(6.95 \mathrm{~g})$, respectively. The petroleum ether fraction showed the higher cytotoxic effect in cells (Figure.1B). The petroleum ether fraction (1.22g) was subjected to purification by silica gel column $(10 \times 500 \mathrm{~mm}, 200 \mathrm{mesh})$, and eluted with an increasingly polar gradient of petroleum ether/chloroform (1:0, 2:1, 1:1, 1:2, 0:1, each 240mL) and chloroform/acetone (1:0, 2:1, 1:1, 1:2, 0:1, each 240mL), to yield nine Sub-fractions (Subf 1-Subf 9). Of these, Subf.4 (28.72mg) exhibited the higher cytotoxic effect (Figure.1C). Subf.4 fraction $(28.72 \mathrm{mg}$ ) was further divided into five fractions (Subf4-1-Subf4-5) using semi-preparative C18 HPLC. Cytotoxic assay indicated that Subf4-2 (3.32mg) exhibited the highest effect (Fig.1D). Moreover, the ingredient in Subfr.4-2 was identified as ginkgolic acid C13:0 (Figure.1F), ESI-MS $\mathrm{m} / \mathrm{z} 319.5[\mathrm{M}-\mathrm{H}]^{-}$and purity of $>85 \%$, on the basis of HPLC-MS and comparison with the standard of ginkgolic acids (GAs).

\subsection{Semi-preparative HPLC purification of GA C13:0}


Semi-preparative HPLC was carried out using C18 HPLC silica semi-prep column (250×19 mm I.D., 5 $\mu \mathrm{m}$, Waters, USA) on a Waters LC-1525 HPLC system (Milford, MA, USA) equipped with an UV detector. A gradient elution was performed by varying the proportion of solvent A (water containing 3\% acetic acid) to solvent B (methanol). The gradient program was as follows: $0-10$ min with $80 \%$ solvent $\mathrm{B}, 10-20 \mathrm{~min}$ from $80 \%$ to $85 \% \mathrm{~B}, 20-30 \mathrm{~min}$ from $85 \%$ to $90 \%$ B, 30-40 min from $90 \%$ to $91 \%$ B, $40-50$ min with $91 \%$ to $92 \%$ B and $50-60$ min from $92 \%$ to $93 \% \mathrm{~B}$. The flow rate of the mobile phase was $6.0 \mathrm{~mL} / \mathrm{min}$, and the UV detection wavelength was $280 \mathrm{~nm}$, and the sample injection volume was $2.0 \mathrm{~mL}$ at $28^{\circ} \mathrm{C}$ column temperature.

\subsection{Cell lines and culture conditions}

The MCF-7 and 4T-1 breast cancer cells were purchased from the cell bank of the Chinese Academy of Sciences (Shanghai, China). The cells were carrying green fluorescent protein (GFP) in the cytoplasm. The cells were grown and maintained in RPMI-1640 cell culture medium supplemented with $10 \%$ fetal bovine serum and $1 \%$ antibiotics in a tissue culture apparatus with atmosphere at $37^{\circ} \mathrm{C}$ containing $5 \% \mathrm{CO} 2$. All experiments were repeated three times independently and the representative images were shown.

\subsection{Cytotoxic assay (MTT)}

The cytotoxic effect of extracts, fractions, subfractions, subfraction-4 and GA C13:0 were measured using MTT. The MCF-7 and 4T- 1 cells (1×105/well) were cultured in sterile 96 well plates and treatment with samples containing different concentrations. After the plate was incubated for $24 \mathrm{~h}, 10 \mu \mathrm{L} /$ well MTT reagents were added to each well and incubated for $4 \mathrm{~h}$. The medium was carefully removed and formazan crystals were dissolved in $110 \mu \mathrm{L}$ of DMSO. The optical density was determined at $490 \mathrm{~nm}$ with SpectraMax190 spectrophotometer (Molecular Devices, Sunnyvale, CA, USA).The 50\% inhibitory concentration (IC50) was defined as the most cytotoxicity.

\subsection{Trypan blue dye exclusion assay}

This method was done as demonstrated previously [42]. Briefly, cells were plated into 96 well plates $\left(1 \times 10^{5} /\right.$ well). After treatment with the samples for $24 \mathrm{~h}$, cells were harvested washing with phosphate-buffer-solution (PBS) to remove debris and treated with $1 \mathrm{X}$ trypsin/EDTA solution. The suspended cells were centrifuged for $5 \mathrm{~min}$ at $1200 \mathrm{rpm}$ and then resuspended the cells in $100 \mu \mathrm{L}$ PBS to obtain single-cell suspension. The cell suspension was loaded into the hemocytometer with the trypan blue $(0.4 \%, 100 \mu \mathrm{L})$, which was to stain dead cells. The cell death rate was determined from the ratio of the number of nonviable (stained) cells to the total number of cells.

\subsection{Anti-proliferative assay}

The GA C13:0 was diluted in the medium with $0.05 \%$ DMSO and filtered with pore of $0.22 \mu \mathrm{m}$ and then stored in the dark at $-20^{\circ} \mathrm{C}$ until use. Cells were treated with the samples at various concentrations ranging from 400 to $50 \mu \mathrm{M}$ for $24 \mathrm{~h}$, and the control containing the medium with $0.05 \%$ DMSO. Cells percent survival (\%) were counted and images were captured on inverted fluorescence microscope (Eclipse 90i, Nikon, Japan). 


\subsection{DAPI staining assay}

Cells were plated into 96 well plates $\left(1 \times 10^{5} /\right.$ well). After treatment with GA C13:0 for 24h, cells washed with PBS and morphological changes and apoptotic cells (\%) were observed by inverted fluorescence microscopy after staining with $0.1 \mu \mathrm{g} / \mathrm{mL} 4^{\prime}$, 6-diamidino-2-phenylindole (DAPI).

\subsection{TUNEL assay}

The terminal deoxynucleotidyl transferase-mediated dUTP-biotin nick end labeling (TUNEL) assay for detection of apoptosis was performed by using Apoptosis Detection Kit (Millipore, Chemicon $\AA$, USA). According to the manufacturer's instructions, Cells were plated in 96 well plates $\left(1 \times 10^{5} /\right.$ well) and treated with GA C13:0 for $24 \mathrm{~h}$. Cells washed with PBS and fixed in $2 \%$ paraformaldehyde at $4^{\circ} \mathrm{C}$ for $30 \mathrm{~min}$. Fixed cells were then permeabilized in $0.1 \%$ Triton X-100 and labeled with fluorescein 12-d UTP using terminal deoxynucleotidyl transferase. Apoptotic cells were observed using inverted fluorescence microscope.

\subsection{Wound healing assay}

Cells were plated into 24 well plates $\left(5 \times 10^{5} /\right.$ well) with serum-free medium overnight and $1 \mathrm{ml}$ pipette tip was used to vertically scratch the surface of cells at the center of each well. The wells were washed with PBS and images were taken under inverted bright microscope at $0 \mathrm{~h}$ time point, then GA C13:0 was added to various groups and images were taken at 48h time point post-scratch at the same positions. The image software was used to calculate the percentage of gap closures.

\subsection{Quantification of reverse transcription polymerase chain reaction ( $q P C R$ )}

Total RNA was extracted using Trizol reagent (Invitrogen Life Technologies, Carlsbad, CA, USA) and reverse transcription into the first-strand complementary DNA (cDNA) using the reverse transcriptase kit (Ta Ka Ra, China) according to the instructions. Primer pairs for CYP1A1, CYP1B1 and AhR are listed in Table 1. The PCR reactions were performed using a Bio-Rad iQ5 (Bio-Rad Laboratories, Inc., Hercules, CA, USA). The PCR amplification was performed in a total reaction volume of $20 \mu \mathrm{L}$, containing $1.0 \mu \mathrm{L}$ of cDNA sample, $2.0 \mu \mathrm{L}(10 \mu \mathrm{M})$ of each primer, $10 \mu \mathrm{l} 2 \times$ All-in-One qPCR Mix, $4.6 \mu \mathrm{L}$ diethylpyrocarbonate $\mathrm{H}_{2} \mathrm{O}$ and $0.4 \mu \mathrm{l}$ $50 \times$ ROX Reference Dye (Trans Gen Biotech, Beijing, China).The cycling parameters were: initial denaturation at $94^{\circ} \mathrm{C}$ for $10 \mathrm{~min}$, followed by 36 cycles of denaturation at $94^{\circ} \mathrm{C}$ for $30 \mathrm{sec}$, annealing at $58^{\circ} \mathrm{C}$ for $20 \mathrm{sec}$ and a final extension at $72^{\circ} \mathrm{C}$ for $20 \mathrm{sec}$. Light Cycler 480 analysis software (Roche Light Cycler 480, Hoffmann La Roche, Ltd., Basel, Switzerland) was used to obtain the $\mathrm{Ct}$ values. The $\Delta \Delta \mathrm{CT}$ method was used to analyze the relative expression of CYP1A1, CYP1B1 and AhR. Reactions were run in three independent experiments. 


\begin{tabular}{|c|c|c|}
\hline Primer name & Squence $\left(5^{\prime}-3^{\prime}\right)$ & Organism \\
\hline \multirow[t]{2}{*}{ CYP1A1-For } & TGGATGAGAACGCCAATGTC & \\
\hline & & human \\
\hline CYP1A1-Rev & TGGGTTGACCCATAGCTTCT & \\
\hline \multirow[t]{2}{*}{ CYP1B1-For } & GGCTGGATTTGGAGAACGTA & \\
\hline & & human \\
\hline CYP1B1-Rev & GTCCTTGGGAATGTGGTAGC & \\
\hline \multirow[t]{2}{*}{ AhR- For } & ACATCACCTACGCCAGTCGC & \\
\hline & & human \\
\hline AhR- Rev & TCTATGCCGCTTGGAAGGAT & \\
\hline \multirow[t]{2}{*}{ CYP1A1-For } & TCCTGTCCTCCGTTACCTGC & \\
\hline & & mouse \\
\hline CYP1A1-Rev & ACCTGCCACTGGTTCACAAA & \\
\hline \multirow[t]{2}{*}{ CYP1B1-For } & GATGTGCCTGCCACTATTACGG & \\
\hline & & mouse \\
\hline CYP1B1-Rev & GCACACAGAGACTATCGCACT & \\
\hline \multirow[t]{2}{*}{ AhR- For } & CGCTGAAACATGAGCAAATTGG & \\
\hline & & mouse \\
\hline AhR- Rev & ACAGCTTAGGTGCTGAGTCACAGG & \\
\hline
\end{tabular}

Western blotting was done as described previously [43]. Briefly, proteins were separated by $10 \%$ sodium dodecyl sulfate polyacrylamide gel electrophoresis (SDS-PAGE). The SDS-PAGE gel was transferred to polyvinylidene fluoride (PVDF) membranes. The membranes were incubated with different primary antibodies, followed with secondary antibody (horseradish peroxidase conjugated anti-rabbit IgG).Antibody binding was detected by chemoluminescence regent. Bands were scanned and quantified by automatic chemiluminescence image analysis system (Tanon Science and Technology Co., Ltd., Shanghai, China).All experiments were conducted in triplicate.

\subsection{Statistical analysis}

Data were expressed as the means \pm standard deviation (SD) of three replications and were evaluated by one-way analysis of variance (ANOVA). Statistical analysis and bar graphs were performed by the GraphPad Prism version 5.0 (Graph PadTM Software, SanDiego, CA, USA). ${ }^{*} \mathrm{P}<0.05$ and ${ }^{* *} \mathrm{P}<0.01$ were regarded as significant. 


\section{Conclusion}

In summary, the present study demonstrated that the natural compound of GA C13:0, which was isolated from the GBE by cytotoxicity guided isolation exhibited anti-proliferation, pro-apoptosis and anti-migration effects in MCF-7 and 4T-1 cells. Meanwhile, the assessment of cytotoxicity of GA C13:0 indicated no cytotoxicity was found at concentrations below $100 \mu \mathrm{M}$. Furthermore, the inhibition mechanisms of GA C13:0 that were involved with up-regulating Bax/Bcl-2 ratio and the Apaf-1 protein expression in the mitochondrial apoptosis pathway, down-regulating Snail, MMP-2, MMP-9, Vimentin and up-regulating E-cadherin protein expression to reveal anti-EMT effects and up-regulating CYP1B1 and AhR protein expression in the AhR pathway. Notably, the possible associations among the mitochondrial apoptosis pathway, EMT pathway as well as the vital regulatory role of CYP1B1 in MCF-7 and 4T-1 cells are needed further studies to be confirmed. Our results indicate that the more concentrations of GA maybe beneficial to apply in the natural anticancer agent research field.

Supplementary Materials: Supplementary materials can be found at www.mdpi.com/link.

Acknowledgments: This study was funded by the 'Financial support for selected researchers back from abroad (2011)' project of the Liaoning Province under grant number 521082403-880303-88030312004.

Author Contributions: Da-Yu Zhou and Shi-Liang Ma conceived and designed the experiments; Da-Yu Zhou, Chun-Ying Jiang, Cheng-Hao Fu, Ping Chang, Jia-Di Wu, Ke-Xin Zheng performed the experiments; Da-Yu Zhou and Xiao-Hui Zhao analyzed the data. Shi-Liang Ma and Xiao-Hui Zhao contributed reagents/materials. Da-Yu Zhou drafted the manuscript.

Conflicts of Interest: The authors have declared no conflict of interest.

\section{Abbreviations}

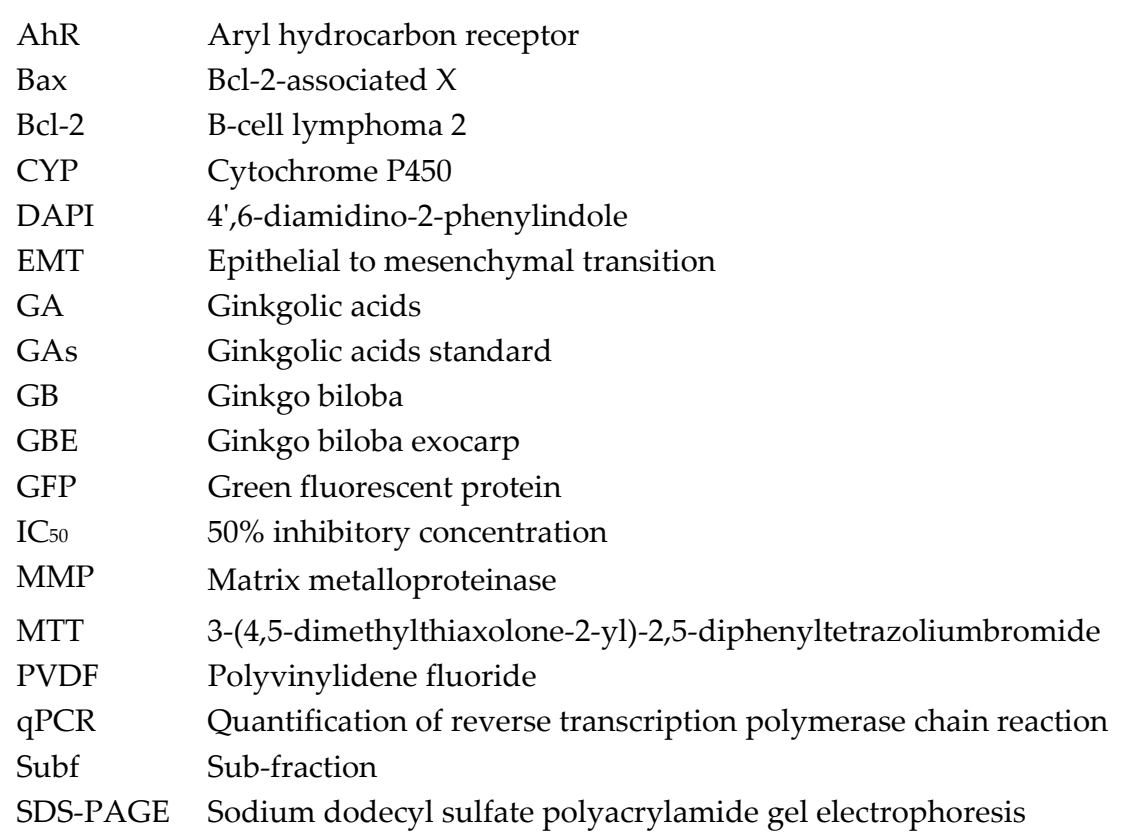

\section{References}

1. Hutchinson, L., Breast cancer: challenges, controversies, breakthroughs. Nature Reviews Clinical Oncology 2010, 7, (12), 669-70.

2. Lochhead, P.; Chan, A. T.; Nishihara, R.; Fuchs, C. S.; Beck, A. H.; Giovannucci, E.; Ogino, S., Etiologic field effect: reappraisal of the field effect concept in cancer 
predisposition and progression. Modern Pathology An Official Journal of the United States \& Canadian Academy of Pathology Inc 2015, 28, (1), 14.

3. Pasqualini, J. R., The selective estrogen enzyme modulators in breast cancer: a review. Biochimica Et Biophysica Acta 2004, 1654, (2), 123-143.

4. Karimi, Z.; Jessri, M.; Houshiar-Rad, A.; Mirzaei, H. R.; Rashidkhani, B., Dietary patterns and breast cancer risk among women. Public Health Nutrition 2014, 17, (5), 1098-1106.

5. Liu, R. H., Dietary bioactive compounds and their health implications. Journal of Food Science 2013, 78 Suppl 1, (s1), A18.

6. Roleira, F. M.; Tavares-Da-Silva, E. J.; Varela, C. L.; Costa, S. C.; Silva, T.; Garrido, J.; Borges, F., Plant derived and dietary phenolic antioxidants: anticancer properties. Food Chemistry 2015, 183, 235-258.

7. Han, X.; Tao, S.; Lou, H., Dietary Polyphenols and Their Biological Significance. International Journal of Molecular Sciences 2007, 8, (9), 950-988.

8. Chemat; Farid; Vian; Abert, M.; Cravotto; Giancarlo, IJMS, Vol. 13, Pages 8615-8627: Green Extraction of Natural Products: Concept and Principles. 2012.

9. Yang, N.; Sun, Y.; Wang, Y.; Long, C.; Li, Y.; Li, Y., Proteomic analysis of the low mutation rate of diploid male gametes induced by colchicine in Ginkgo biloba L. Plos One 2013, 8, (10), e76088.

10. Feng, X. L.; Zhang, L. T.; Zhu, H. M., Comparative anticancer and antioxidant activities of different ingredients of Ginkgo biloba extract (EGb 761). Planta Medica 2009, 75, (08), 792-796.

11. Man, S.; Gao, W.; Wei, C.; Liu, C., Anticancer drugs from traditional toxic Chinese medicines. Phytotherapy Research Ptr 2012, 26, (10), 1449-1465.

12. Cao, C.; Su, Y.; Han, D.; Gao, Y.; Zhang, M.; Chen, H.; Xu, A., Ginkgo biloba exocarp extracts induces apoptosis in Lewis lung cancer cells involving MAPK signaling pathways. Journal of Ethnopharmacology 2017, 198, 379.

13. Zhang, C.; Ling, F.; Yi, Y. L.; Zhang, H. Y.; Wang, G. X., Algicidal activity and potential mechanisms of ginkgolic acids isolated from Ginkgo biloba exocarp on Microcystis aeruginosa. Journal of Applied Phycology 2014, 26, (1), 323-332.

14. Zhang, Z. B.; Ruan, C. C.; Chen, D. R.; Zhang, K.; Yan, C.; Gao, P. J., Activating transcription factor 3 SUMOylation is involved in angiotensin II-induced endothelial cell inflammation and dysfunction. Journal of Molecular \& Cellular Cardiology 2016, 92, 149.

15. Lü, J.-M.; Yan, S.; Jamaluddin, S.; Weakley, S. M.; Liang, Z.; Siwak, E. B.; Yao, Q.; Chen, C., Ginkgolic acid inhibits HIV protease activity and HIV infection in vitro. Medical Science Monitor International Medical Journal of Experimental \& Clinical Research 2012, 18, (8), BR293-BR298.

16. Lee, J. H.; Kim, Y. G.; Ryu, S. Y.; Cho, M. H.; Lee, J., Ginkgolic acids and Ginkgo biloba extract inhibit Escherichia coli O157:H7 and Staphylococcus aureus biofilm formation. International Journal of Food Microbiology 2014, 174, 47-55.

17. Baek, S. H.; Ko, J. H.; Lee, J. H.; Kim, C.; Lee, H.; Nam, D.; Lee, J.; Lee, S. G.; Yang, W. M.; Um, J. Y., Ginkgolic Acid Inhibits Invasion and Migration and TGF- $\beta$-Induced EMT of Lung Cancer Cells Through PI3K/Akt/mTOR Inactivation. Journal of Cellular 
Physiology 2017, 232, (2).

18. Qiao, L.; Zheng, J.; Jin, X.; Wei, G.; Wang, G.; Sun, X.; Li, X., Ginkgolic acid inhibits the invasiveness of colon cancer cells through AMPK activation. Oncology Letters 2017, 14, (5), 5831-5838.

19. Berg, K., Evaluation of the cytotoxic and mutagenic potential of three ginkgolic acids. Toxicology 2015, 327, 47-52.

20. Hamdoun, S.; Efferth, T., Ginkgolic acids inhibit migration in breast cancer cells by inhibition of NEMO sumoylation and NF- $\mathrm{kB}$ activity. Oncotarget 2017, 8, (21), 35103-35115.

21. Zhou, C.; Li, X.; Du, W.; Feng, Y.; Kong, X.; Li, Y.; Xiao, L.; Zhang, P., Antitumor effects of ginkgolic acid in human cancer cell occur via cell cycle arrest and decrease the Bcl-2/Bax ratio to induce apoptosis. Chemotherapy 2010, 56, (5), 393-402.

22. Zhao, X. D.; Dong, N.; Man, H. T.; Fu, Z. L.; Zhang, M. H.; Kou, S.; Ma, S. L., Antiproliferative effect of the Ginkgo biloba extract is associated with the enhancement of cytochrome P450 1B1 expression in estrogen receptor-negative breast cancer cells. Biomedical Reports 2013, 1, (5), 797.

23. Olech, M.; Nowak, R.; Pecio, Ł.; R, Ł.; Malm, A.; Rzymowska, J.; Oleszek, W., Multidirectional characterisation of chemical composition and health-promoting potential of Rosa rugosa hips. Natural Product Research 2016, 31, (6), 1.

24. Yamaguchi, M., The botanical molecule p-hydroxycinnamic acid as a new osteogenic agent: insight into the treatment of cancer bone metastases. Molecular $\mathcal{E}$ Cellular Biochemistry 2016, 421, (1-2), 193-203.

25. Yang, X. M.; Wang, Y. F.; Li, Y. Y.; Ma, H. L., Thermal stability of ginkgolic acids from Ginkgo biloba and the effects of ginkgol C17:1 on the apoptosis and migration of SMMC7721 cells. Fitoterapia 2014, 98, 66-76.

26. Wang, S.; He, M.; Li, L.; Liang, Z.; Zou, Z.; Tao, A., Cell-in-Cell Death Is Not Restricted by Caspase-3 Deficiency in MCF-7 Cells. Journal of Breast Cancer 2016, 19, (3), 231-241.

27. Amaravadi, R. K.; Thompson, C. B., The Roles of Therapy-Induced Autophagy and Necrosis in Cancer Treatment. Clinical Cancer Research An Official Journal of the American Association for Cancer Research 2007, 13, (24), 7271-9.

28. Wajant, H., The Fas signaling pathway: more than a paradigm. Science 2002, 296, (5573), 1635.

29. Schmitt, E.; Paquet, C.; Beauchemin, M.; Bertrand, R., Bcl-xES, a BH4- and $\mathrm{BH} 2$-containing antiapoptotic protein, delays Bax oligomer formation and binds Apaf-1, blocking procaspase-9 activation. Oncogene 2004, 23, (22), 3915.

30. Khan, N.; Adhami, V., H, Apoptosis by dietary agents for prevention and treatment of cancer. Biochemical Pharmacology 2008, 76, (11), 1333-1339.

31. Weschesoldato, D. E.; Swan, R. Z.; Chung, C. S.; Ayala, A., The apoptotic pathway as a therapeutic target in sepsis. Current Drug Targets 2007, 8, (4), -.

32. Thiery, J. P., Epithelial-mesenchymal transitions in tumour progression. Nature Reviews Cancer 2002, 2, (6), 442.

33. Lee, J. M.; Dedhar, S.; Kalluri, R.; Thompson, E. W., The Epithelial-Mesenchymal Transition: New Insights in Signaling, Development, and Disease. Journal of Cell 
Biology 2006, 172, (7), 973.

34. Gao, D.; Vahdat, L. T.; Wong, S.; Chang, J. C.; Mittal, V., Microenvironmental Regulation of Epithelial-Mesenchymal Transitions in Cancer. Cancer Research 2012, 72, (19), 4883-9.

35. Go, R.-E.; Hwang, K.-A.; Choi, K.-C., Cytochrome P450 1 family and cancers. The Journal of Steroid Biochemistry and Molecular Biology 2015, 147, (2), 24-30.

36. Mense, S. M.; Hei, T. K.; Ganju, R. K.; Bhat, H. K., Phytoestrogens and Breast Cancer Prevention: Possible Mechanisms of Action. Environmental Health Perspectives 2008, 116, (4), 426-433.

37. Androutsopoulos, V.; Arroo, R. R.; Hall, J. F.; Surichan, S.; Potter, G. A., Antiproliferative and cytostatic effects of the natural product eupatorin on MDA-MB-468 human breast cancer cells due to CYP1-mediated metabolism. Breast Cancer Research 2008, 10, (3), R39.

38. Androutsopoulos, V. P.; Mahale, S.; Arroo, R. R.; Potter, G., Anticancer effects of the flavonoid diosmetin on cell cycle progression and proliferation of MDA-MB 468 breast cancer cells due to CYP1 activation. Oncology Reports 2009, 21, (6), 1525.

39. Chang, I.; Mitsui, Y.; Kim, S. K.; Sun, J. S.; Jeon, H. S.; Kang, J. Y.; Kang, N. J.; Fukuhara, S.; Gill, A.; Shahryari, V., Cytochrome P450 1B1 inhibition suppresses tumorigenicity of prostate cancer via caspase-1 activation. Oncotarget 2017.

40. Saini, S.; Hirata, H.; Majid, S.; Dahiya, R., Functional significance of cytochrome P450 $1 \mathrm{~B} 1$ in endometrial carcinogenesis. Cancer Research 2009, 69, (17), 7038.

41. Yeo-Jung, K.; Hyoung-Seok, B.; Ye, D. J.; Sangyun, S.; Donghak, K.; Young-Jin, C., CYP1B1 Enhances Cell Proliferation and Metastasis through Induction of EMT and Activation of Wnt/ $\beta$-Catenin Signaling via Sp1 Upregulation. Plos One 2016, 11, (3), e0151598.

42. Piccinini, F.; Tesei, A.; Arienti, C.; Bevilacqua, A., Cell Counting and Viability Assessment of 2D and 3D Cell Cultures: Expected Reliability of the Trypan Blue Assay. Biological Procedures Online 2017, 19, (1), 8.

43. Zhao, X.; Zhou, D.; Liu, Y.; Li, C.; Zhao, X.; Li, Y.; Li, W., Ganoderma lucidum polysaccharide inhibits prostate cancer cell migration via the protein arginine methyltransferase 6 signaling pathway. Molecular Medicine Reports 2018. 